\title{
BMJ Open How much evidence is there that political factors are related to population health outcomes? An internationally comparative systematic review
}

\author{
Max Barnish, ${ }^{1}$ Michelle Tørnes, ${ }^{2}$ Becky Nelson-Horne ${ }^{3}$
}

To cite: Barnish M, Tørnes M, Nelson-Horne B. How much evidence is there that political factors are related to population health outcomes? An internationally comparative systematic review. BMJ Open 2018;8:e020886. doi:10.1136/ bmjopen-2017-020886

- Prepublication history and additional material for this paper are available online. To view these files, please visit the journal online (http://dx.doi org/10.1136/bmjopen-2017020886).

An abstract from this systematic review was presented at the Society for Social Medicine and Population Health Annual Scientific Meeting, Glasgow, September, 2018.

Received 29 November 2017 Revised 20 August 2018 Accepted 23 August 2018

\section{Check for updates}

(c) Author(s) (or their employer(s)) 2018. Re-use permitted under CC BY-NC. No commercial re-use. See rights and permissions. Published by BMJ.

${ }^{1}$ Institute of Health Research, Exeter Medical School, University of Exeter, Exeter, UK ${ }^{2}$ Ageing Clinical and Experimental Research (ACER) team, School of Medicine, Medical Sciences and Nutrition, University of Aberdeen, Aberdeen, UK

${ }^{3}$ Independent Scholar, Glasgow, UK

Correspondence to

Dr Max Barnish;

m.s.barnish@exeter.ac.uk

\section{ABSTRACT}

Objectives To provide a 7-year update of the most recent systematic review about the relationships between political features and population health outcomes.

Setting Internationally comparative scholarly literature. Data sources Ten scholarly bibliographic databases plus supplementary searches in bibliographies and Google Scholar were used to update a previous systematic review. The final search was conducted in November 2017.

Primary and secondary outcome measures Any population health outcome measure, apart from healthcare spending.

Results 73 unique publications were identified from the previous systematic review. The database searches to update the literature identified 45356 raw records with 35207 remaining following de-duplication. 55 publications were identified from supplementary searches. In total, 258 publications proceeded to full-text review and 176 were included in narrative synthesis. 85 studies were assessed at low risk of bias, 89 at moderate risk of bias and none at high risk of bias. Assessment could not be conducted for two studies that had only book chapters. No metaanalysis was conducted. 102 studies assessed welfare state generosity and 79 found a positive association. Of the 17 studies that assessed political tradition, 15 were found to show a positive association with the left-of-centre tradition. 44 studies assessed democracy and 34 found a positive association. 28 studies assessed globalisation and 14 found a negative association, while seven were positive and seven inconclusive.

Conclusions This review concludes that welfare state generosity, left-of-centre democratic political tradition and democracy are generally positively associated with population health. Globalisation may be negatively associated with population health, but the results are less conclusive. It is important for the academic public health community to engage with the political evidence base in its research as well as in stakeholder engagement, in order to facilitate positive outcomes for population health.

\section{INTRODUCTION}

\section{Conceptualising politics}

Politics is an omnipresent feature of modern civilisations worldwide and has been described as the "practice of the art or science of directing and administrating states'. ${ }^{1}$ At a

\section{Strengths and limitations of this study}

- We offer the largest systematic review on the political determinants of population health.

- The use of a systematic review design offers a robust and reproducible method that minimises potential reviewer bias.

- Our review also involved searching 10 major scholarly databases in addition to relevant supplementary searches.

- The internationally comparative approach ensures relevance to readers worldwide.

- Resources meant it was infeasible to conduct a new review from inception. So an update of a 2010 review was done.

global level, political views and systems differ substantially. However, they can usefully be conceptualised in terms of two axes. The first is democracy versus autocracy, which conceptualises the extent to which the population decides, either directly or indirectly, its government and governance. ${ }^{2}$ The second is the left versus right axis, which conceptualises the extent to which a government intervenes in an attempt to secure social goals (progressive, left wing) or focuses on economic freedom and minimal state intervention (conservative, right wing). ${ }^{3}$

Opportunities for politics to influence population health

One of the founding fathers of social medicine, Rudolph Virchow, said that 'Medicine is a social science, and politics nothing but medicine at a larger scale'. ${ }^{4}$ Indeed, many pathways to public health impact are polit$\mathrm{ical}^{5}$ although the precise structures by which these operate differ between countries. Especially in developed countries, the existence of formal evidence-based systems is common in the licensing of medicines and medical devices (for example, the European Medicines Agency and the Food and Drug 
Administration (United States of America)) and the development of national clinical guidelines and the approval for specific medicines and medical devices to be used in public sector health systems (for example, the National Institute of Health and Care Excellence on behalf of the National Health Service in England and Wales).

Nevertheless, as Virchow said, health means far more than medicine. For example, social and economic inequalities are strong predictors of health inequali$\operatorname{ties}^{67}$ and increased income inequality at a societal level has been shown to be strongly associated with worse health outcomes including life expectancy, infant mortality, obesity and mental health, as well as social outcomes such as trust, education level and social mobility. ${ }^{8}$ However, there is evidence that political ideology and personal interests can exert substantial influences on policy-making processes relevant to health, leading to marked evidencepolicy gaps. ${ }^{9}$ Political influences can operate at a variety of levels, such as national governments, devolved governments (see online supplementary file 1 for an example) and local authorities, which have taken a greater role in public health in recent years in many countries. ${ }^{10}$

\section{Existing evidence about the relationship between politics and population health}

While single-country evidence such as the review by ScottSamuel et $a l^{11}$ on the health effects of Thatcherism, and recent studies on the effects of Conservative Party austerity in England ${ }^{12} 13$, can be valuable, internationally comparative evidence allows us to transcend the particularities of individual countries. The most recent internationally comparative systematic review that assessed a wide range of political features was published in 2011 featuring literature search up to April 2010 (the 2010 review) ${ }^{14}$ It did not include a risk of bias assessment. It assessed four key political features: democracy, welfare state, left-of-centre political tradition and globalisation.

The "contestability' 15 inherent in a democracy may be health-promoting due to the potential electoral consequences of unpopular policies. Left-of-centre political tradition, and an advanced welfare state which is a key marker thereof, ${ }^{3}$ may be health-promoting due to a greater focus on active state intervention to address social, economic and health inequalities, ${ }^{6-8}$ and consequent greater alignment to public health mission statements, such as that of the European Public Health Association. ${ }^{16}$ Globalisation is a multi-faceted concept, but may encompass trade liberalisation and free markets, which are more favoured by the political right than the left. ${ }^{3}$ The 2010 review suggested that globalisation was negatively associated with population health outcomes, while democracy, welfare state and left-of-centre political tradition positively correlated with such outcomes. The majority of the studies had been published in the 5-year period up to the search, indicating an active field of research. This suggests that the 2010 review is likely to be considerably out of date now.

\section{Aims}

We offer an updated systematic review investigating relationships between four key political features (democracy, welfare state, political tradition and globalisation) and population health outcomes. This represents the largest systematic review of evidence in this field to date.

\section{METHODS \\ Design}

A narrative systematic review design was used following the internationally accepted Preferred Reporting Items for Systematic Reviews and Meta-Analyses (PRISMA) guidelines. ${ }^{17} \mathrm{MB}$ was the lead reviewer. Proportionate independent second review was performed by $\mathrm{BN}-\mathrm{H}$ for each stage in the review process, whereby this author independently appraised $20 \%$ of records for each stage. There were few disagreements, and where these arose, they were resolved by discussion.

\section{Data sources}

As ours was an updated systematic review, all included studies from the 2010 review proceeded directly to the fulltext review stage. An update search was conducted on 10 scholarly databases from 2010 to April 2017 (MEDLINE, AMED, EMBASE, PsycINFO (all Ovid), CINAHL, Philosopher's Index (both Ebsco), Science Citation Index Expanded, Social Sciences Citation Index, Emerging Sources Citation Index (all Web of Science) and Sociological Abstracts (ProQuest)), following the conceptual search strategy shown in box 1 , from which search strings for the syntax of each database were developed. The full MEDLINE search strategy is shown in online supplementary file 2. Supplementary searches back to 2006 were conducted on Google Scholar and in relevant bibliographies. The final search was conducted in November 2017.

\section{Inclusion criteria}

Records were screened initially by title and abstract, and then in full text form for potential inclusion according to the following criteria:

- Peer-reviewed journal article in a scientific journal or a scholarly book or chapter

- Study of human populations either at the individual or ecological level

- Present at least one measure of a political exposure, conceptualised in terms of the welfare state, political tradition, democracy or globalisation. These political features were defined exactly following Muntaner et $a l$, and listed in table $1 .^{14}$

\section{Box 1 Conceptual search strategy}

((democracy OR autocracy OR welfare regime OR welfare state OR welfare capitalism $O R$ politics $O R$ political tradition $O R$ internationality $O R$ globalization) AND (health OR health services OR population health $\mathrm{OR}$ public health $\mathrm{OR}$ health economics $\mathrm{OR}$ health expenditure)) 
Table 1 Definitions of political exposure variables

\begin{tabular}{|c|c|}
\hline Exposure variable & Definition \\
\hline Welfare state & $\begin{array}{l}\text { 'if the analysis included welfare } \\
\text { regimes or welfare state indicators } \\
\text { (eg, universal health coverage), but } \\
\text { not measures of political ideology } \\
\text { (eg, along the left-right dimension)' }\end{array}$ \\
\hline Political tradition & $\begin{array}{l}\text { 'if the study included variables } \\
\text { referring to the left-right political } \\
\text { dimension } \\
\text { (eg, social democratic/egalitarian } \\
\text { left vs liberal/conservative/right } \\
\text { political parties in government)' }\end{array}$ \\
\hline Democracy & $\begin{array}{l}\text { 'if the hypotheses tested involved } \\
\text { democratic institutions or political } \\
\text { rights' }\end{array}$ \\
\hline Globalisation & $\begin{array}{l}\text { 'if the article examined how high, } \\
\text { middle, andor low countries are } \\
\text { integrated through global networks } \\
\text { of trade, foreign investment, and } \\
\text { multinational corporations' }\end{array}$ \\
\hline
\end{tabular}

Source of definitions: Muntaner et al. ${ }^{14}$

- Present at least one measure of a population health outcome. Healthcare spending alone was not considered an eligible outcome

- Use any quantitative empirical design to link the exposure to the outcome

- Present a comparison involving at least two countries

\section{Data extraction}

Results were classified into one of four political themes: welfare state, political tradition, democracy and globalisation, as per table 1 . Studies were allowed to contribute to more than one political theme. The following information was extracted for each included study: (i) bibliographic details, (ii) sampling frame, (iii) years of study, (iv) design, (v) political themes to which the study contributes, (vi) measure(s) of political exposures, (vii) measure(s) of population health outcome measures and (iix) classification of results (positive, negative or inconclusive association between the political exposure and population health outcome measures).

\section{Risk of bias assessment}

Risk of bias assessment was conducted at the study level using the Threats to Validity Tool, ${ }^{18}$ using the configuration of Barnish and Barnish, ${ }^{19}$ with one modification. Loss-to-follow-up was not considered relevant for the body of studies included in this review. Following Barnish et $a t^{20}$ the categories were set as (i) low risk of bias (high quality) if $\geq 70 \%$ of eligible items were assessed as at low risk of bias, (ii) moderate risk of bias (moderate quality) for $40 \%-69 \%$ and (iii) high risk of bias (low quality) for $\leq 39 \%$. This assessment could not be conducted for studies that only comprised book chapters, since the tool is not suitable, and format incompatibility could introduce bias into the assessment.

\section{Data synthesis}

In light of differences in political contexts between countries, and in terms of how political exposures and population health outcomes were measured, narrative synthesis was considered more appropriate than meta-analysis. Studies were grouped by political theme. In addition to our base case analysis, certain scenario analyses were conducted to further explore the data:

1. Studies that take economic factors into consideration, for each of the four themes except globalisation.

2. Studies that include developing countries, for each of the four themes.

3. Studies looking at general health or quality of life, for each of the four themes.

4. Studies using a welfare regime classification scheme, for the welfare state theme.

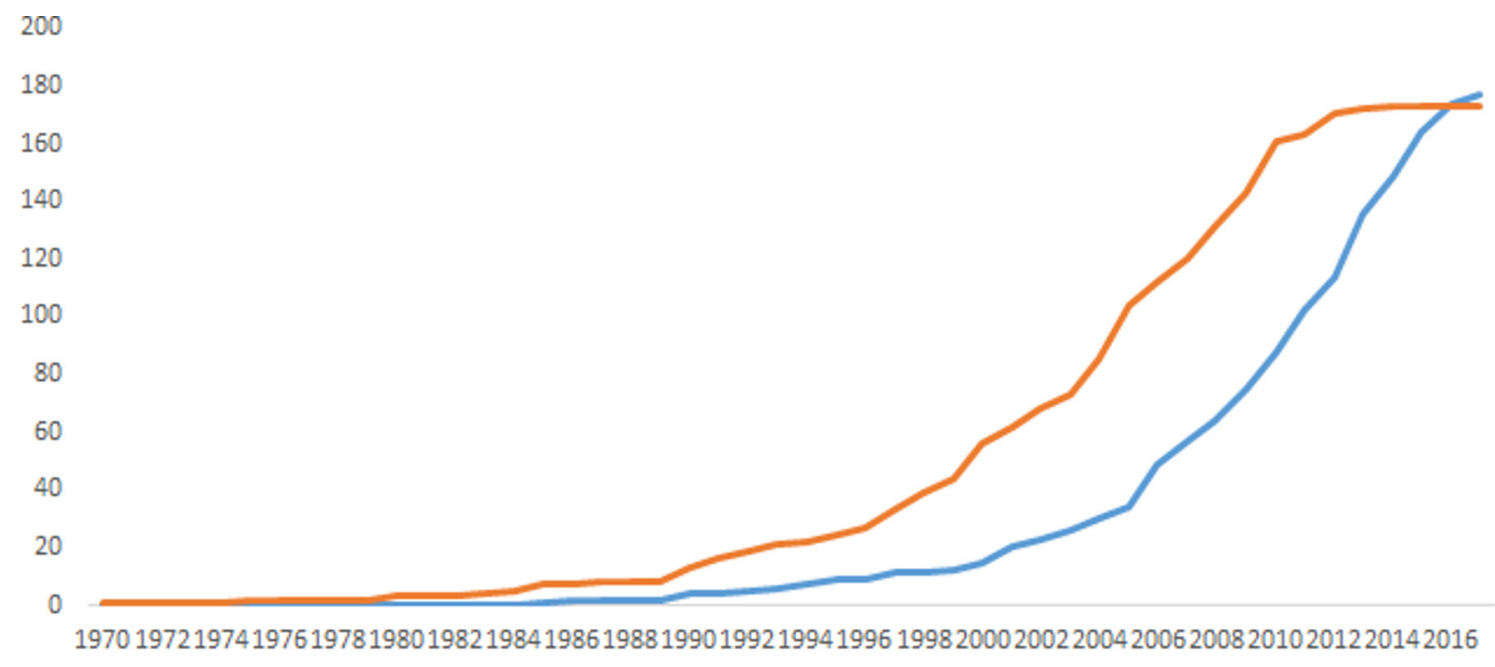

Cumulative $\mathrm{N}$ studies by publication year ㄴ C umulative $\mathrm{N}$ studies by final study year

Figure 1 Accumulation of evidence on the political determinants of population health over time. 


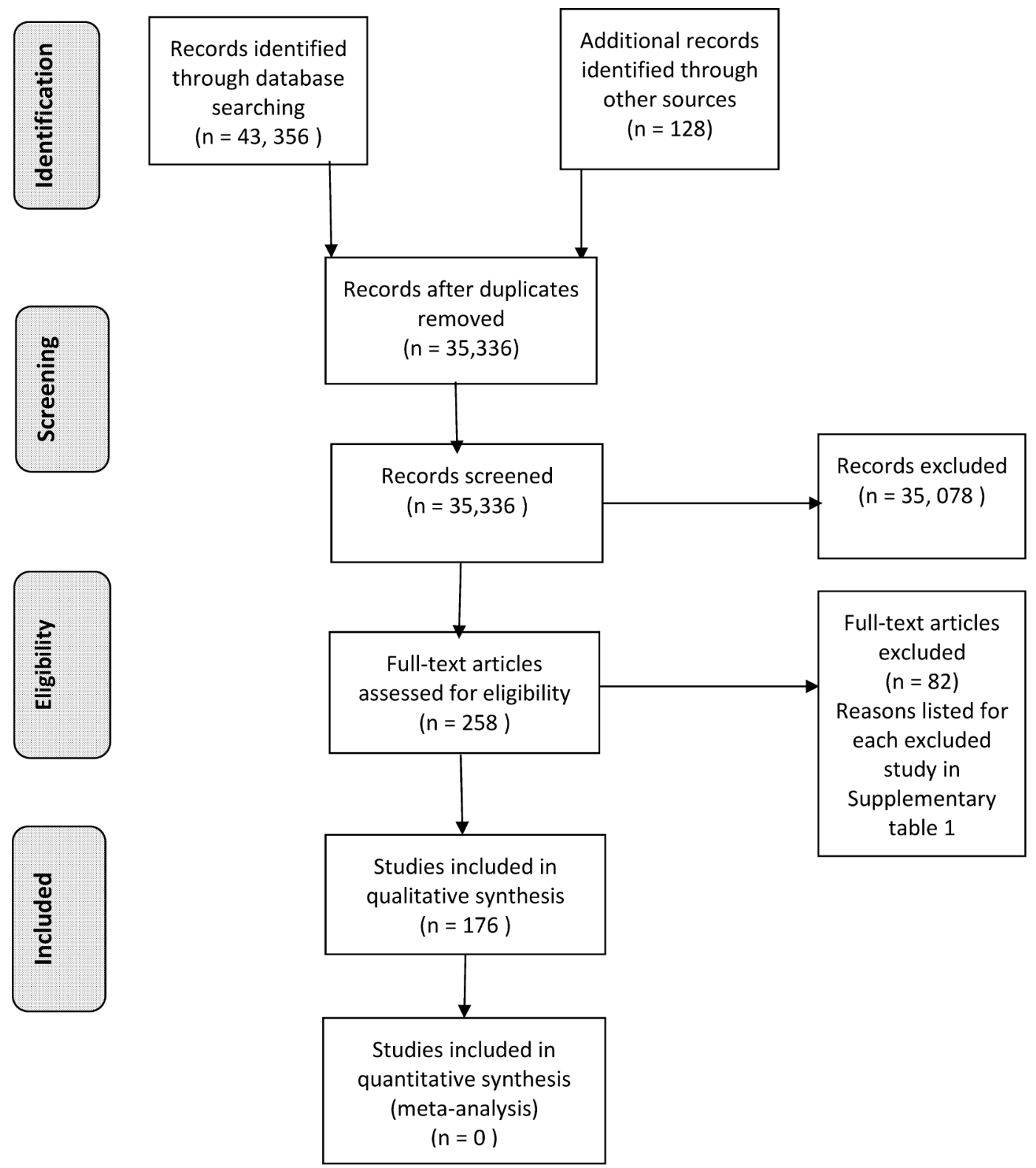

From: Moher D, Liberati A, Tetzlaff J, Altman DG, The PRISMA Group (2009). Preferred Reporting Items for Systematic Reviews and MetaAnalyses: The PRISMA Statement. PLoS Med 6(7): e1000097. doi:10.1371/journal.pmed1000097

For more information, visit www prisma-statement.org.

Figure 2 Preferred Reporting Items for Systematic Reviews and Meta-Analyses 2009 flow diagram.

5. Studies using a political tradition classification scheme, for the political tradition theme.

The scenario analysis on economic factors was not conducted for the globalisation theme because globalisation itself has a dominant economic component, so this is already measured. A formal test of economic mediation was not required - it was sufficient that studies took economic factors into consideration.

\section{Patient and public involvement}

This is a systematic review of a broad range of population health outcomes and could not be represented by one patient group. Therefore, patients were not involved in the conduct of the study. There was no recruitment since this is a systematic review. The project director (MB) shall respond to reputable media requests and may approach selected media outlets about the possibility of disseminating the research findings more broadly.

\section{RESULTS}

\section{Search results}

Seventy-three de-duplicated records came from the 2010 review. Update database searches yielded 43356 records in total, of which 35207 remained following de-duplication. 
Supplementary searches on Google Scholar and in bibliographies yielded 55 additional records. From 35333 unique records, 255 proceeded to full-text screening and all were retrieved. Out of them, 176 studies were included in our review (online supplementary file 3), of which 106 came from our update searches and 70 from the 2010 review. 82 studies were excluded at the full-text review stage (online supplementary file 4 ). Studies were published in final form with a median of 6years (IQR 4-8) after the year of final data collection and the longest lag was 20 years (figure 1 ). The most recent data included in the analyses was collected in 2014. A PRISMA flowchart (figure 2) and PRISMA checklist (online supplementary file 5) are provided. Eighty-five studies (49\%) were assessed at low risk of bias, $89(51 \%)$ at moderate risk of bias and none at high risk of bias. Risk of bias assessment could not be conducted for two studies $(1 \%$ of total) whose only included publications came in the form of book chapters. Study-level risk of bias profiles are provided in online supplementary file 6 .

\section{Welfare state}

A total of 102 studies addressed the welfare state theme. Of these, $79(77 \%)$ provided evidence that was favourable about the association of increased welfare state generosity with population health, 20 (20\%) were inconclusive and three $(3 \%)$ were negative. Most studies either classified welfare state generosity in terms of a welfare regime classification or in terms of expenditure on health and social care. Welfare regime classifications did vary between studies, but often an 'advanced', for example, Nordic ${ }^{21}$ welfare regime was compared with liberal and also marketdriven/conservative alternatives. Health outcomes for welfare state studies included self-rated general health, quality of life, prevalence of chronic conditions, mental health, life expectancy and child and infant mortality. Online supplementary file 7 provides study-level details.

Among studies that took economic factors into consideration $(n=83), 82 \%$ found a more generous welfare state to be positively associated with population health. Among studies including developing countries $(n=23), 83 \%$ were found to have a positive association. Among studies that used a general health or quality of life outcome $(\mathrm{n}=32), 69 \%$ showed a positive association. Considering only studies that used a welfare regime classification $(n=45), 73 \%$ exhibited positive association.

\section{Political tradition}

A total of 17 studies addressed the political tradition theme. Of these, 15 (88\%) were positive about the association of left-of-centre political tradition with population health, while two $(12 \%)$ were inconclusive. Ways in which political tradition was measured included political tradition classification of the ruling government, duration in power by different parties, voter partisanship, proportion of seats held by left-wing or left-of-centre parties and working class power. Population health outcomes included life expectancy, infant and child mortality, life expectancy, older adult mortality, general self-rated health and successful implementation of effective health policies. Online supplementary file 8 provides study-level details.

All studies in the political tradition theme considered economic factors, so no scenario analysis was conducted on this factor. Among studies including developing countries, all $(n=6)$ found left-of-centre political tradition to be positively associated with population health outcomes. Among studies that used a general health or quality of life outcome, all $(n=6)$ the studies found this association. Among studies that used a political tradition classification scheme $(\mathrm{n}=8), 88 \%$ showed this association.

\section{Democracy}

A total of 44 studies addressed the democracy theme. Of these, $34(77 \%)$ were positive, eight $(18 \%)$ were inconclusive and two (5\%) negative. Ways in which democracy was measured included political transition to democracy, years of democracy since 1900, the presence of elections and standardised indices such as Polity IV. ${ }^{22}$ Population health outcomes included measures such as general self-rated health, life expectancy, older adult mortality, and successful implementation of effective health policies, while there was a particular focus on infant and child mortality and other child health outcomes. Online supplementary file 9 provides study-level details.

Among studies taking economic factors into consideration $(n=39), 77 \%$ found democracy to be positively associated with population health outcomes. Among studies including developing countries $(n=25), 76 \%$ were found to have this association. Among studies that used a general health or quality of life outcome, all $(n=3)$ exhibited this association.

\section{Globalisation}

A total of 28 studies addressed the globalisation theme. Of these, seven (25\%) were positive, seven $(25 \%)$ were inconclusive and $14(50 \%)$ were negative. Measures of globalisation included world-system role, foreign trade, debt dependency, imports and exports, as well as membership of organisations such as the World Trade Organisation and standardised indices such as the Maastricht Globalisation Index ${ }^{23}$ and the KOF Index. ${ }^{24}$ Many studies measured infant and child health outcomes and mortality, while assessed measures including life expectancy, obesity, water pollution and tobacco smoking rates. Online supplementary file 10 provides study-level results.

All globalisation studies included data from developing countries, so no scenario analysis was performed on this factor. Only one study in this theme assessed general health or quality of life, and found a positive association between globalisation and health-related quality of life.

\section{Health outcomes}

Table 2 provides an overview of the results for each political exposure theme subdivided by health outcome. For the welfare state political exposure, the most commonly 
Table 2 Overview of overall result classification by political exposure and health outcome

\begin{tabular}{|c|c|c|c|c|c|c|c|c|c|c|c|c|}
\hline & \multicolumn{3}{|c|}{ Welfare state } & \multicolumn{3}{|c|}{ Political tradition } & \multicolumn{3}{|c|}{ Democracy } & \multicolumn{3}{|c|}{ Globalisation } \\
\hline & $\mathbf{P}$ & $\mathbf{N}$ & $\mathbf{I}$ & $\mathbf{P}$ & $\mathbf{N}$ & $\mathbf{I}$ & $\mathbf{P}$ & $\mathbf{N}$ & $\mathbf{I}$ & $\mathbf{P}$ & $\mathbf{N}$ & I \\
\hline Birth weight & 4 & 0 & 0 & 2 & 0 & 0 & 0 & 0 & 0 & 0 & 0 & 0 \\
\hline Cancer & 1 & 0 & 0 & 0 & 0 & 0 & 0 & 0 & 0 & 0 & 1 & 0 \\
\hline Cerebrovascular disease & 0 & 0 & 0 & 0 & 0 & 0 & 0 & 0 & 0 & 0 & 1 & 0 \\
\hline Child mortality & 13 & 0 & 0 & 3 & 0 & 0 & 5 & 0 & 5 & 2 & 2 & 2 \\
\hline Child well-being & 1 & 0 & 0 & 0 & 0 & 0 & 0 & 0 & 0 & 0 & 0 & 1 \\
\hline Chronic conditions & 5 & 1 & 2 & 1 & 0 & 0 & 0 & 0 & 0 & 0 & 0 & 0 \\
\hline Diabetes & 0 & 0 & 0 & 0 & 0 & 0 & 0 & 0 & 0 & 0 & 1 & 0 \\
\hline Fertility and reproductive health & 1 & 0 & 0 & 0 & 0 & 0 & 2 & 0 & 1 & 0 & 0 & 0 \\
\hline General health & 24 & 0 & 11 & 4 & 0 & 0 & 4 & 0 & 0 & 1 & 0 & 0 \\
\hline Health behaviours & 1 & 0 & 0 & 0 & 0 & 0 & 0 & 0 & 0 & 0 & 0 & 0 \\
\hline Healthcare burden/need & 3 & 0 & 0 & 0 & 0 & 0 & 0 & 0 & 0 & 0 & 0 & 0 \\
\hline Heart disease & 0 & 0 & 0 & 0 & 0 & 0 & 0 & 0 & 0 & 0 & 1 & 0 \\
\hline Health inequalities* & 11 & 0 & 2 & 2 & 0 & 0 & 0 & 0 & 0 & 0 & 0 & 0 \\
\hline HIV/AIDS & 1 & 0 & 0 & 0 & 0 & 0 & 1 & 0 & 0 & 0 & 1 & 0 \\
\hline Homicide and suicide & 0 & 0 & 1 & 0 & 0 & 0 & 0 & 0 & 0 & 0 & 1 & 0 \\
\hline Immunisation/vaccination rates & 0 & 0 & 0 & 0 & 0 & 0 & 0 & 1 & 0 & 0 & 1 & 0 \\
\hline $\begin{array}{l}\text { Implementation of effect health } \\
\text { policy }\end{array}$ & 0 & 0 & 0 & 0 & 0 & 1 & 1 & 0 & 0 & 0 & 0 & 0 \\
\hline Infant mortality & 16 & 0 & 2 & 8 & 0 & 0 & 15 & 1 & 4 & 4 & 3 & 3 \\
\hline Life expectancy/adult mortality & 21 & 2 & 5 & 8 & 0 & 1 & 16 & 1 & 3 & 4 & 1 & 1 \\
\hline Maternal health & 0 & 1 & 0 & 0 & 0 & 0 & 0 & 0 & 0 & 0 & 0 & 0 \\
\hline Mental health & 9 & 0 & 1 & 0 & 0 & 0 & 1 & 0 & 0 & 0 & 0 & 0 \\
\hline Nutrition, overweight and obesity & 0 & 0 & 0 & 0 & 0 & 0 & 1 & 0 & 2 & 0 & 5 & 1 \\
\hline Oral health & 2 & 0 & 0 & 0 & 0 & 0 & 0 & 0 & 0 & 0 & 0 & 0 \\
\hline Physical activity/health & 1 & 0 & 0 & 2 & 0 & 0 & 1 & 0 & 0 & 0 & 0 & 0 \\
\hline Pneumonia & 0 & 0 & 0 & 0 & 0 & 0 & 0 & 0 & 0 & 0 & 1 & 0 \\
\hline Smoking & 0 & 0 & 1 & 1 & 0 & 1 & 0 & 0 & 0 & 0 & 1 & 0 \\
\hline Tuberculosis & 2 & 0 & 0 & 0 & 0 & 0 & 1 & 0 & 0 & 0 & 0 & 2 \\
\hline Water pollution & 0 & 0 & 0 & 0 & 0 & 0 & 0 & 0 & 0 & 0 & 2 & 0 \\
\hline Well-being of the unemployed & 1 & 0 & 1 & 0 & 0 & 0 & 0 & 0 & 0 & 0 & 0 & 0 \\
\hline
\end{tabular}

Columns denote political exposure variables; rows denote health outcome variables.

*This is additionally indirectly measured by many of the other outcomes.

I, inconclusive; $N$, negative; $P$, positive.

studied health outcomes were general health $(\mathrm{n}=35,24$ positive, 11 negative), life expectancy/adult mortality ( $\mathrm{n}=28,21$ positive, two inconclusive, five negative), child mortality $(\mathrm{n}=13,13$ positive) and health inequalities ( $\mathrm{n}=13,11$ positive, two inconclusive), noting that the last of the outcomes is also measured indirectly through many of the other health outcomes in the table. For political tradition, studies were more dispersed across outcomes, although the two outcomes that were considerably more studied than the others were life expectancy/ adult mortality ( $\mathrm{n}=9$, eight positive, one inconclusive) and infant mortality ( $\mathrm{n}=8$, eight positive). For democracy, by far the most widely studied outcomes were life expectancy/adult mortality $(\mathrm{n}=20,16$ positive, one negative, three inconclusive) and infant mortality ( $\mathrm{n}=20,15$ positive, one negative, four inconclusive). Less consistent results were found for child mortality ( $\mathrm{n}=10$, five positive, five inconclusive).

For globalisation, studies were quite dispersed across outcomes and the pattern of results differed between outcomes, consistent with the evidence base in the review being least conclusive for the globalisation outcome. For child mortality $(n=6)$, the results were equally split between positive $(n=2)$, negative $(n=2)$ and inconclusive $(n=2)$. The results were also split for infant mortality ( $n=10$, four positive, three negative, three inconclusive). For adult mortality/life expectancy, there was a pattern in favour of a positive association with globalisation $(n=6$, 
four positive, one negative, one inconclusive), while for nutritional, overweight and obesity-related outcomes, the pattern was in favour of a negative association with globalisation ( $\mathrm{n}=6,0$ positive, one inconclusive, five negative).

\section{DISCUSSION}

\section{Summary of findings}

We present a body of evidence from 176 internationally comparative scholarly studies that together provides powerful evidence that key political characteristics are related to a range of population health outcomes. The evidence was favourable about a positive association of population health with increased welfare state generosity, left-of-centre democratic political tradition and democracy, supported by over three-quarters of eligible studies. Twice as much evidence supported a negative association of population health with globalisation than a positive association, although a quarter of studies were inconclusive.

\section{Scenario analyses}

Scenario analyses showed that (i) most studies considered economic factors and excluding those that did not made little difference to the results, (ii) apart from the globalisation theme, a minority of studies included developing countries but the results of those that did were generally consistent with those that did not, (iii) classification schemes for welfare state and political tradition made little difference to the results and (iv) the proportion of studies using general health or quality of life outcome measures was relatively low, but the results were directionally consistent with the wider set of studies.

In terms of analytical strategies to consider economic factors, a popular approach was to incorporate gross domestic product (GDP) or gross national product (GNP) into the analytical modelling. Another approach used by some studies was to incorporate a measure of household income into the analysis. The former approach considers economic factors at the societal level, while the latter considers economic factors at the family level. The scenario analysis of studies including developing countries considered all studies that included developing countries, and was not restricted to studies that considered exclusively developing countries. The rationale for this was to provide an analysis in which any results particular to affluent, for example Organisation for Economic Co-operation and Development (OECD), countries, were excluded, thereby offering a broader and more representative insight into the relationship between political factors and global population health. Indeed, this was a systematic review of internationally comparative studies, in order to provide a global perspective. The scenario analysis provided for studies that included developing countries helps safeguard our findings against the limitation that the observed findings are only applicable to affluent or developed countries. Many studies included data from a wide range of countries, and combined with the approach of not excluding studies that did not study exclusively developing countries from the scenario analysis, this offered a safeguard against the potential dominance of data from a narrow set of countries. We therefore do not consider that there is any evidence that the analyses in this report are dominated by data from specific countries.

\section{Risk of bias assessment}

Eighty-five studies (49\%) were assessed at low risk of bias, $89(51 \%)$ at moderate risk of bias and none at high risk of bias. However, low risk of bias of individual studies does not mean that there is necessarily low risk of bias across studies, especially when grouping so many heterogeneous studies. The three types of potential bias that were found quite often were chance, group equivalence and potential conflict of interest. Most studies were very large; however, they tended not to provide a rationale for their sample size or provide information to let us assess whether there may have been under-powered or indeed overpowered to detect associations. Group equivalence is very hard to achieve in studies such as the ones eligible for our review, since it would entail countries being similar in most other ways except the political variable of interest. Substantive conflicts of interest were rare, but more of an issue was an absence of funding statements or declarations as to whether there were any conflicts of interest. This absence was particularly notable among studies published in social science journals. No study declared any party political members among the authors, yet it seems incongruous to believe that no author among 176 health policy studies was a member of a political party. Rather, it seems that political conflicts of interest are seldom declared, when potentially they should be.

\section{Strengths}

We offer the largest systematic review on the political determinants of population health, and the first wideranging internationally comparative systematic review of similar scope since 2010. The use of a systematic review design offers a robust and reproducible method that minimises potential reviewer bias in the selection and evaluation of studies for potential inclusion. ${ }^{25}$ Our review also involved searching 10 major scholarly databases and this very thorough coverage of the literature is reflected in a very low proportion of studies being identified from supplementary searches. All publications identified for full-text screening were successfully obtained. Conducting searches back to 2006 as part of our update enabled us to include a further ten eligible studies published before the search date of the 2010 review. We independently evaluated all studies from the 2010 review and allowed studies to contribute to multiple themes, allowing further relevant data to be included. The internationally comparative approach ensures relevance to readers worldwide and transcends the limitations associated with single-country studies. Unlike the authors of the 2010 review, we were able to provide a risk of bias assessment. 


\section{Limitations}

Resources precluded a new review from inception and this required us to update an English-language only review from 2010. Moreover, conducting an update required us to maintain consistency with the 2010 review in terms of inclusion criteria and precluded us from considering a wider range of grey literature sources, such as OECD reports, which may have relevant data. Moreover, the categorical form of data extraction in terms of positive, inconclusive or negative results followed the previous review and was necessitated by its scope and scale. Limiting reviews to the English language may not exert systematic bias in systematic reviews, at least according to evidence from reviews of healthcare interventions. ${ }^{26}$ The diversity of political and health-system contexts as well as measures of political exposures and population health outcomes precluded meta-analysis. The internationally comparative approach increases relevance for an international readership, yet it introduces complexities in the mapping between political characteristics and political parties in both systematic and idiosyncratic ways. ${ }^{27-31}$ Public health policy evidence is typically observational, which reflects real-world situations. Observational studies do not intrinsically overstate effect sizes ${ }^{32}$ and can be highly valuable. ${ }^{5}$ Causative inference can be made more complicated by different causal pathways, different confounders and different covariates, although systems such as Bradford Hill $^{33}$ may be used as a starting point. Studies did not regularly report their study design thoroughly or consistently in terms of recognised design labels beyond the basics such as ecological versus individual studies, which limited the level of detail in which information on study design could be extracted.

\section{Comparison with previous reviews}

Our review offers a seven-and-a-half-year search advance on the most recent internationally comparative systematic review to offer an equivalent scope. The 2010 review by Muntaner $e t a l^{14}$ included 73 studies, of which 70 were eligible for our review. Three were excluded from our review since they only included healthcare spending as an outcome. We considered that to be circular, since healthcare spending was also frequently used by studies as a marker of welfare state generosity. To these 70 studies, we added a further 106 (10 of which were dated prior to the search of the 2010 review), giving a total of 176 studies in our review. Those added by our update constituted $60 \%$ of the total $58 \%$ if the 10 studies we added from prior to 2010 were removed from the numerator and denominator), demonstrating how the scale of the evidence base for the political determinants of population health has more than doubled over the past seven-and-a-half years.

The strength of evidence that welfare state generosity is positively associated with population health has increased slightly ( $77 \%$ vs $72 \%$ positive), while the number of studies has more than tripled (102 vs 32). The strength of evidence that left-of-centre political tradition is positively associated with population health has increased markedly $(88 \%$ vs
$60 \%$ positive), while the number of studies has increased modestly ( 17 vs 12 ). Notably, far fewer studies have explicitly studied political tradition than the welfare state, which is one of the key markers of political tradition. The strength of evidence that democracy is positively associated with population health is largely unchanged $(77 \%$ vs $78 \%)$, while the number of studies has increased substantially (44 vs 27 ). The strength of evidence that globalisation is negatively associated with population health has weakened $(50 \%$ vs $75 \%$ negative), while the number of studies has increased sevenfold (28 vs 4 ).

A prior review in the interim ${ }^{34}$ had found that the strength of evidence for the benefits of welfare state generosity was greater for studies assessing spending patterns than welfare regime typologies. We did not find a strong effect $-73 \%$ of studies assessing regime typologies were positive compared with $77 \%$ of studies irrespective of how the welfare state was measured. The Nordic model found in Scandinavia was presented by most studies as the example of an advanced welfare state. However, classifications used in these typologies are imperfect, and in many ways the Scottish system (see online supplementary file 1) could be argued to represent a more advanced welfare state, since Norway, for example, does not offer universal free healthcare at point of use. Our findings on the welfare state and political tradition were also consistent with those of Scott-Samuel et $a l^{11}$ regarding Thatcherism in the United Kingdom, which found a widening of health inequalities resultant from the introduction of reduced state welfare provision and increased privatisation and pro-market policies.

\section{Perspectives on the role of academia}

The presentation of an evidence base from 176 studies associating political factors with a range of population health outcomes offers an opportunity for the reader to reflect on the role of public health academia, in light of university research impact policies in many countries, and recent scholarly debates on the role of academia. Academic public health has a long pro-social political history. ${ }^{35} \mathrm{~A}$ recent BMJ article ${ }^{36}$ offers insight into ongoing debate on the relative priority of action and research in public health, while Smith $e t a l^{37}$ reflect on whether or not advocacy is a disciplinary duty for public health academics, and Kapilashrami $e t a l^{38}$ provide an interesting example of an advocacy programme. Indeed, there has been reticence both at the individual $^{4}$ and organisational ${ }^{39}$ level to engage in advocacy. Meanwhile, Schafer ${ }^{40}$ offers insight into the potential of partnership approaches to knowledge translation with stakeholders, which may be valuable but also depends on ideological match.

\section{Recommendations for research}

It is important that health research increasingly focuses on real-world contexts to supplement more idealised studies. ${ }^{5}$ Health research that does not consider political and cultural factors may lack relevance and generalisability, ${ }^{41}$ especially research into the social determinants of 
health. Further research into the globalisation and political exposure theme may help elucidate the evidence base in this area, and potentially distinguish different influences that may explain why globalisation seems to be able to be associated both positively and negatively with population health across health outcomes.

\section{Implications for policy and practice}

Clinicians and decision makers should be aware of the context in which they work, and the political influences on medicine and health outcomes. They should seek to find ways to increase the use of evidence in decisions impacting on health. Ideas such as "health in all policies $^{42}$ are worthwhile, but only if they are genuinely put into action and not seen as a 'tick box' exercise.

\section{CONCLUSION}

In conclusion, we present a systematic review of 176 studies that demonstrates that welfare state, left-of-centre democratic political tradition and democracy are generally positively associated with a range of population health outcomes.

Contributors MB was the project director and project manager. The study was conceptualised by MB with input from MT and BN-H. Searches were conducted by MB. Study selection, data extraction and quality assessment were conducted by MB with proportionate second review from BN-H. Data interpretation was led by MB with input from MT and BN-H. MB wrote the first draft of the paper. MT and BN-H commented on the draft manuscript and thereby contributed important revisions. All tables, figures and supplementary files were made by MB. All authors approved the submission. $M B$ is the guarantor.

Funding The authors have not declared a specific grant for this research from any funding agency in the public, commercial or not-for-profit sectors.

Disclaimer All views presented in this article are the authors' own, and not necessarily those of their institutions nor bodies that fund their other research projects.

Competing interests The authors have personal views and/or memberships on the political left that we do not consider conflict with the vision of public health. MB is a member of the Labour Party (United Kingdom), MT is a member of the Scottish National Party (SNP, a centre-left pro-independence party that forms the devolved government of Scotland) and BN-H is not a member of any party. This work was not done on behalf of any political party and is not endorsed, influenced or supported in any way by the parties of which authors are members. $\mathrm{MB}$ is a social democrat/ liberal socialist. MT is a democratic socialist and supports Scottish independence. $\mathrm{BN}-\mathrm{H}$ is a democratic socialist. The authors engage in appropriate activities to promote public health and social justice.

Patient consent Not required.

Provenance and peer review Not commissioned; externally peer reviewed. Data sharing statement № further data are available.

Open access This is an open access article distributed in accordance with the Creative Commons Attribution Non Commercial (CC BY-NC 4.0) license, which permits others to distribute, remix, adapt, build upon this work non-commercially, and license their derivative works on different terms, provided the original work is properly cited, appropriate credit is given, any changes made indicated, and the use is non-commercial. See: http://creativecommons.org/licenses/by-nc/4.0/.

\section{REFERENCES}

1. McLean I, McMillan A. Oxford concise dictionary of politics. Oxford: Oxford University Press, 2003.

2. Cartledge P. Democracy: a life. Oxford: Oxford University Press, 2015.

3. Gauchet M. Right and left. In: Nora P, Kritzman LD, eds. Realms of memory: conflicts and divisions. New York: Columbia University Press, 1997.
4. Mackenbach JP. Politics is nothing but medicine at a larger scale: reflections on public health's biggest idea. J Epidemiol Community Health 2009;63:181-4.

5. Barnish MS, Turner S. The value of pragmatic and observational studies in health care and public health. Pragmat Obs Res 2017;8:49-55.

6. Rowlingson K. Does income inequality cause health and social problems? York: Joseph Rowntree Foundation, 2011.

7. Marmot M. The Marmot review: fair society, healthy lives. London: The Marmot Review, 2010.

8. Wilkinson R, Pickett K. The spirit level: why equality is better for everyone. London: Penguin, 2010.

9. Ferrie JE. Evidence and policy: mind the gap. Int $J$ Epidemiol 2015;44:1-7.

10. Reijneveld SA. The return of community-based health and social care to local government: governance as a public health challenge. Eur $J$ Public Health 2017;27:1.

11. Scott-Samuel A, Bambra C, Collins C, et al. The impact of Thatcherism on health and well-being in Britain. Int $\mathrm{J}$ Health Serv 2014;44:53-71

12. Watkins J, Wulaningsih W, Da Zhou C, et al. Effects of health and social care spending constraints on mortality in England: a time trend analysis. BMJ Open 2017;7:e017722.

13. Hiam L, Dorling D, Harrison D, et al. What caused the spike in mortality in England and Wales in January 2015? J R Soc Med 2017;110:131-7.

14. Muntaner C, Borrell C, Ng E, et al. Politics, welfare regimes, and population health: controversies and evidence. Sociol Health IIIn 2011;33:946-64.

15. Dahl RA. Polyarchy: participation and opposition. New Haven: Yale University Press, 1971.

16. European Public Health Association. Who we are. https://eupha.org/ who-we-are (Accessed 24 Feb 2018).

17. Moher D, Liberati A, Tetzlaff J, et al. Preferred reporting items for systematic reviews and meta-analyses: the PRISMA statement. BMJ 2009;339:b2535.

18. Daley DJ, Myint PK, Gray RJ, et al. Systematic review on factors associated with medication non-adherence in Parkinson's disease. Parkinsonism Relat Disord 2012;18:1053-61.

19. Barnish MS, Barnish J. High-heeled shoes and musculoskeletal injuries: a narrative systematic review. BMJ Open 2016;6:e010053.

20. Barnish MS, Whibley D, Horton SMC, et al. Roles of cognitive status and intelligibility in everyday communication in people with parkinson's disease: a systematic review. J Parkinsons Dis 2016;6:453-62.

21. Kildal N, Kuhnle S. The Nordic welfare model and the idea of universalism. In: Kildal N, Kuhnle S, eds. Normative foundations of the welfare state: the Nordic experience. London: Routledge, 2006:13-33.

22. Marshall MG, Jaggers K. Polity IV project: political regime characteristics and transitions. Severn, MD: Center for Systemic Peace, 2006.

23. Figge L, Martens P. Globalisation continues: the Maastricht globalisation index revisited and updated. Globalizations 2014;11:875-93.

24. Dreher A. Does globalization affect growth? Evidence from a new index of globalization. Appl Econ 2006;38:1091-110.

25. Uman LS. Systematic reviews and meta-analyses. J Can Acad Child Adolesc Psychiatry 2011;20:57-9.

26. Jüni $\mathrm{P}$, Holenstein F, Sterne J, et al. Direction and impact of language bias in meta-analyses of controlled trials: empirical study. Int $J$ Epidemiol 2002;31:115-23.

27. Goldfarb M. Liberal? Are we talking about the same thing? BBC News, 2010.

28. Thorpe A. A history of the British Labour Party. Basingstoke: Palgrave Macmillan, 2008.

29. Scott-Samuel A, Bambra C. A week is a long time in politics: the health implications of Jeremy Corbyn's UK labour party leadership victory. Int J Health Serv 2016;46:141-8.

30. Barnish M, Morgan HM, Barnish J. The 2016 HIGh Heels: Health effects And psychosexual BenefITS (HIGH HABITS) study: systematic review of reviews and additional primary studies. BMC Public Health 2017;18:37.

31. Office of the Premier. B.C. bans mandatory high heels in the workplace. Victoria, British Columbia: Office of the Premier, 2017.

32. Concato J, Shah N, Horwitz RI. Randomized, controlled trials, observational studies, and the hierarchy of research designs. $N$ Engl J Med 2000;342:1887-92.

33. Hill AB. The environment and disease: association or causation? Proceed R Soc Med 1965;58:295-300. 
34. Bergqvist $\mathrm{K}$, Yngwe MA, Lundberg $\mathrm{O}$. Understanding the role of welfare state characteristics for health and inequalities - an analytical review. BMC Public Health 2013;13:1234.

35. Horton R. Offline: medicine and marx. Lancet 2017;390:2026.

36. Capewell S, Cairney P, Clarke A. Should action take priority over further research on public health? BMJ 2018;360:k292.

37. Smith KE, Stewart EA. Academic advocacy in public health: Disciplinary 'duty' or political 'propaganda'? Soc Sci Med 2017;189:35-43.

38. Kapilashrami A, Smith KE, Fustukian S, et al. Social movements and public health advocacy in action: the UK people's health movement. J Public Health 2016;38:413-6.
39. Chauvin JB. Advocacy: the silence of Europe's public health associations is deafening. Eur J Public Health 2016;26:2.

40. Schafer P. Community-academic partnerships and social change. In: O'Campo P, Dunn JR, eds. Rethinking social epidemiology: towards a science of change. Dordrecht: Springer Netherlands, 2011:285-304.

41. Levecque K, Van Rossem R, De Boyser K, et al. Economic hardship and depression across the life course: the impact of welfare state regimes. J Health Soc Behav 2011;52:262-76.

42. Ollila E. Health in All Policies: from rhetoric to action. Scand $J$ Public Health 2011;39(6 Suppl):11-18. 